\title{
Variabilidade genética entre e dentro de grupos de Euterpe spp. com
}

\section{base em microssatélites}

\author{
Santos, Jussara Fernanda ${ }^{1,3}$; Keny Henrique Mariguele ${ }^{2}$; Adriana Pereira ${ }^{2}$; Fabio Martinho \\ Zambonim ${ }^{2}$; Giorgini Augusto Venturieri ${ }^{1}$
}

${ }^{1}$ Programa de Pós Graduação em Agroecossistemas, Universidade Federal de Santa Catarina, Florianópolis, Santa Catarina, Brasil; ${ }^{2}$ Empresa de Pesquisa Agropecuária e Extensão Rural de Santa Catarina (EPAGRI), Itajaí, Santa Catarina, Brasil; ${ }^{3}$ jussaraflo@yahoo.com.br

Santos, Jussara Fernanda; Keny Henrique Mariguele; Adriana Pereira; Fabio Martinho Zambonim; Giorgini Augusto Venturieri (2020) Variabilidade genética entre e dentro de grupos de Euterpe spp. com base em microssatélites. Rev. Fac. Agron. Vol 119 (1): 1-7. https://doi.org/10.24215/16699513e042

\begin{abstract}
Objetivou-se neste trabalho estudar a diversidade entre e dentro de acessos da coleção de Euterpe spp. da Empresa de Pesquisa Agropecuária e Extensão Rural de Santa Catarina - Estação Experimental de Itajaí (EPAGRI-EEI) e identificar grupos dissimilares que possam orientar cruzamentos dirigidos para obtenção de combinações genotípicas desejáveis. Para tal, foram testados 18 marcadores microssatélites, previamente desenvolvidos para Euterpe edulis Mart. Seis deles - EE54, EE59, EE03, EE45, EE52 e EE47 - foram eficientes e empregados na obtenção das estimativas desejadas. Foram revelados em média15 a 4 alelos por grupo, sendo que o conteúdo de informação polimórfica variou de 0,305 a 0,835. A partir da análise de variância foram obtidos valores de variação de $13 \%$ entre grupos, 47 e $40 \%$ entre e dentro dos acessos, respectivamente. O Método bayesiano indicou a formação de quatro grupos e a partir do dendograma com o método Ward, com $50 \%$ do valor de dissimilaridade foi possível identificar os acessos que compõe esses grupos, além de indicar os acessos com dissimilaridade baixa $(\leq 10 \%)$. A diversidade encontrada possibilita a orientação de cruzamentos dirigidos, tanto para formação de híbridos intra e interespecíficos, como para retrocruzamentos.
\end{abstract}

Palavras chave: juçara, açaí, palmeira, híbridos, AMOVA, ward

Santos, Jussara Fernanda; Keny Henrique Mariguele; Adriana Pereira; Fabio Martinho Zambonim; Giorgini Augusto Venturieri (2020) Genetic variability between and within groups of Euterpe spp. based on microsatellites. Rev. Fac. Agron. Vol 119 (1): 1-7. https://doi.org/10.24215/16699513e042

\begin{abstract}
The objective of this article is to study the diversity between and within groups of accesses of the Euterpe spp. germoplasm collection of the Agricultural Research and Rural Extension Company of Santa Catarina - Itajaí Experimental Station and to identify dissimilar groups that could guide targeted crossesin order to obtain desirable genotypic combinations. Therefore, 18 microsatellite markers, previously developed for Euterpe edulis Mart., were tested. Six of them - EE03, EE45, EE47, EE52, EE54 and EE59 - were efficient and used to obtain the desired estimates. The average polymorphic information content varied from 0.305 to 0.835 . Trought the variation analysis, variation values of $13 \%$ were obtained between the groups, 40 and $47 \%$ within and between the accessions. The Bayesian Method indicated the formation of four groups and from the dendogram with the Ward method, $50 \%$ of the dissimilarity value was possible to illustrate them, besides indicating the accesses with low dissimilarity $(\leq 10 \%)$. The diversity found allows the orientation of directed crosses, both for intra and interspecific hybrids formation and for backcrossing.
\end{abstract}

Keywords: juçara, acai, palm, interspecific hybrid, AMOVA, ward

https://revistas.unlp.edu.ar/revagro

Recibido: $11 / 06 / 2019$

Aceptado: 23/10/2019

Disponible on line: $01 / 07 / 2020$

ISSN 0041-8676 - ISSN (on line) 1669-9513, Facultad de Ciencias Agrarias y Forestales, UNLP, Argentina 


\section{INTRODUÇÃO}

As hibridações intra e interespecíficas são técnicas amplamente utilizadas por melhoristas e tem como objetivo principal potencializar a variabilidade genética das espécies vegetais de interesse econômico (Bovi et al., 1987; Cruz et al., 2008). As combinações intraespecificas no gênero Euterpe vêem sendo estudadas tanto para obtenção de palmito como para frutos, o que culminou, por exemplo, com o lançamento da variedade de E. oleracea denominada BRS Pará (Oliveira et al., 2011). A hibridação interespecífica no gênero teve o objetivo de obter a associação das características desejáveis das espécies, como no caso dos híbridos $E$. oleracea x $E$. edulis, que reúnem a característica de perfilhamento de E. oleracea e o sabor do palmito de $E$. edulis (Bovi, 1984; Venturieri et al., 2016).

A técnica de hibridação interespecifica foi aprimorada utilizando a polinização controlada em cruzamentos interespecíficos, recíprocos e retrocruzamentos (Bovi et al., 1987; Campos et al., 1991). A superioridade dos híbridos ( $E$. oleracea $x E$. edulis) em relação aos seus parentais foi constatada a partir da heterose (Bovi, 1984; Bovi et al., 1987), qualidade do palmito (Campos et al., 1991) e viabilidade econômica (Kiyuna et al., 1997). Outra combinação obtida foi o híbrido $E$. precatória x E. espiritosantenses (Oliveira et al., 2010). A maioria dessas hibridações foi desenvolvida apenas para aproveitamento do palmito (Bovi, 1984; Bovi et al., 1987) e atualmente são cogitadas como uma possibilidade de desenvolvimento de genótipos melhorados para produção de frutos (Zambonim et al., 2016).

Quando as combinações de genótipos ocorrem por polinização controlada, geralmente os cruzamentos são orientados por informações baseadas na variabilidade das características fenotípicas dos acessos, sendo mensurada principalmente por índices de diversidade, pela predição de valores genéticos e capacidade específica de combinação (Rocha et al., 2007). Quando os cruzamentos ocorrem por polinização aberta ficam sujeitos ao acaso, sendo impossível prever os genótipos que serão formados. O sucesso dessas combinações está diretamente relacionado com a manutenção da diversidade e a obtenção de melhores gerações que apresentem junção de atributos desejáveis (Lanza et al., 2000). Neste contexto, o prévio conhecimento sobre a distribuição da variabilidade genética entre e dentro grupos de genotipos torna-se fundamental (Aguiar et al., 2007; Furlan et al., 2007; Oliveira \& Silva, 2008).

Os marcadores moleculares do tipo microssatélites, ou sequências de repetição simples (SSR), vêm sendo empregados com sucesso em espécies florestais de interesse econômico (Aguiar et al., 2007; Oliveira et al., 2010). Estes marcadores são úteis para gerar informações que embasam estratégias de conservação (Gaiotto et al., 2003) e de melhoramento (Chagas et al., 2015; Manfio et al., 2012). Por isso, foram desenvolvidos 18 marcadores desse tipo para E. edulis, dos quais sete foram transferidos para $E$. oleracea (Gaiotto et al., 2001) o que possibilitou a aplicação de alguns deles nesta espécie (Oliveira \& Silva, 2008; Oliveira et al., 2010). A partir desses marcadores, a divergência genética entre os acessos de açaizeiros e dos híbridos $E$. precatória x E. espiritosantenses foi estimada com sucesso, sendo a informação útil para quantificação dos estoques de diversidade e previsão das melhores combinações entre os acessos (Oliveira et al., 2010).

O constante crescimento do mercado de palmito e o atual cenário de expansão do mercado de frutos de $E$. oleracea para fabricação da polpa de açaí, consequentemente promove a expansão das áreas cultivadas com esta espécie, diante disso fica evidenciada a necessidade do desenvolvimento de genótipos melhorados e adaptados as condições ambientais de outras localidades. O prévio conhecimento sobre os estoques de diversidade tornase relevante para condução de estratégias de cruzamentos e combinações, sendo uma ferramenta importante que pode determinar o sucesso do programa de melhoramento. Portanto, objetivou-se neste trabalho estudar os acessos da coleção de plantas de Euterpe spp. da Empresa de Pesquisa Agropecuária e Extensão Rural de Santa Catarina Estação Experimental de Itajaí (EPAGRI-EEI) e identificar grupos divergentes para obtenção de combinações com alta diversidade.

\section{MATERIAL E MÉTODOS}

Este trabalho foi realizado na EPAGRI - EEI $\left(26^{\circ} 57^{\prime}\right.$ 06" S 48 45' 38" W), na coleção de plantas de Euterpe spp., a qual foi estabelecida no ano 2000 em Itajai-SC, sendo composta por 81 indivíduos adultos, divididos em três grupos: 48 acessos de $E$. edulis (EE) com procedência do estado de Santa Catarina, 15 acessos de E. oleracea (EO) com procedência da Amazônia e 18 acessos de híbridos $E$. oleracea $\times E$. edulis $(H)$ com procedência de Miracatu-SP.

As análises moleculares foram realizadas no Laboratório de Biologia Molecular da EEI. O DNA genômico foi extraído do tecido foliar fresco das 81 amostras, seguindo o protocolo definido por Doyle (1991), com alterações na adição de SDS na etapa de lise e acetato de sódio $3 \mathrm{M}$ na etapa de precipitação do DNA. A quantidade e a qualidade do DNA foram medidas em biophotometer (Eppendorf, Germany) e foram preparadas soluções de trabalho na concentração de 20ng de DNA por mililitro. Dezoito marcadores, os quais foram desenvolvidos previamente para E. edulis (Gaiotto et al., 2001), foram previamente testados para as amostras de E. oleracea e híbridos. Para as reações de PCR foi utilizada a técnica do iniciador M13 (Schuelke, 2000). As reações continham 40ng de DNA, PCR buffer $1 \mathrm{X}, 1,5 \mathrm{mM}$ de $\mathrm{MgCl}_{2}, 0,20$ $\mathrm{mM}$ de cada dNTP, $0,40 \mu \mathrm{M}$ de iniciador reverso, 0,10 $\mu \mathrm{M}$ de iniciador frontal e $0,4 \mu \mathrm{M}$ de iniciador $\mathrm{M} 13$ marcado com fluorescência,1,0 $U$ de Taq DNA polymerase (Invitrogen), com volume final de $20 \mu \mathrm{L}$. Três diferentes fluorófloros foram usados (6-FAM, VIC e PET - Applied Biosystems, Germany).

As reações foram realizadas em um termociclador Veriti (Applied Biosystems) com o seguinte programa: desnaturação inicial por 5 min a $94^{\circ} \mathrm{C}, 30$ ciclos de $45 \mathrm{~s}$ a $94^{\circ} \mathrm{C}, 45 \mathrm{~s}$ a temperatura de anelamento sugerida por Gaiotto et al. (2001), com exceção do loco EE52 que foi 
$58^{\circ}$, e $1 \mathrm{~min}$ a $72^{\circ} \mathrm{C}, 8$ ciclos de $45 \mathrm{~s}$ a $94^{\circ} \mathrm{C}, 45 \mathrm{~s}$ a $53^{\circ} \mathrm{C}$, e $1 \mathrm{~min}$ a $72^{\circ} \mathrm{C}$ e uma extensão final de $30 \mathrm{~min}$ a $72^{\circ} \mathrm{C}$. A análise dos padrões de fragmentos amplificados foi realizada em analisador genético automático AB 3130 (Applied Biosystems) com capilar de $36 \mathrm{~cm}$ e polímero POP7 seguindo as recomendações do fabricante. Os dados de amplificação de bandas foram anotados em número de pares de bases (pb), conforme a genotipagem fornecida pelo programa GeneMapper 4.0 (Applied Biosystems). O programa GenAlex (Peakall \& Smouse, 2006) foi usado para a avaliação da variabilidade entre e dentro dos grupos de genótipos avaliados, com a significância testada a partir de 999 permutações para a obtenção das seguintes estimativas: número de alelos por loco $\left(\mathrm{N}_{\mathrm{a}}\right)$, número efetivo de alelo $\left(\mathrm{N}_{\mathrm{e}}\right)$ e alelos privados $\left(\mathrm{A}_{\mathrm{p}}\right)$. Com este mesmo programa foi estimada a matriz de distância genética entre os acessos. O conteúdo de informação polimórfica (PIC) (Weir, 1996) foi estimado para cada loco com auxílio do programa Cervus 3.0, onde $p_{i}^{2}$ e a probabilidade do alelo estar em equilíbrio de Hardy Weinberg e $p_{j}^{2}$ a probabilidade do genótipo (Marshall et al., 1998, Kalinowski et al., 2010):

$$
P I C=1-\left(\sum_{i=1}^{n} p_{i}^{2}\right)-\left(\sum_{i=1}^{n-1} \sum_{j=i+1}^{n} 2 p_{i}^{2} p_{j}^{2}\right)
$$

O modelo bayesiano implementado pelo programa Structure (Pritchard et al. 2000; Falush et al. 2003) foi aplicado para inferir o número de grupos. A inferência produzida foi executada com a informação dos grupos pré-definidos, para o modelo misto e com frequência correlacionada. A análise do número de grupos $(K)$ foi executada para valores que variaram de 1 a $20 \mathrm{com}$ dez cadeias independentes, cada cadeia com um comprimento de 50.000 iterações, seguida por 100.000 repetições do número de MCMC (cadeia de Markov e Monte Carlo).

O agrupamento entre os acessos foi construído a partir da matriz estandardizada de divergência genética previamente estimada no GenAlex (Peakall \& Smouse, 2006) e gerado a partir do método Ward, usando distancia euclidiana, com a consistência dos nós testada por 999 permutações sobre todos os locos, com auxílio do programa Past (Hammer et al., 2001).

\section{RESULTADOS}

Entre os 18 SSR testados em E. oleracea e nos híbridos, seis (EE03, EE45, EE47, EE52, EE54, EE59) foram transferidos para as amostras utilizadas e todos foram altamente polimórficos, com PIC acima de 0,5 em $E$. edulis e nos híbridos, exceto EE45 em E. edulis que obteve 0,489. Com exceção do EE54 que foi altamente polimórfico em todos os grupos, os demais SSR foram menos polimórficos em $E$. oleracea, sendo o EE52 monomórfico para este grupo de genótipos (Tabela 1).

A partir do conjunto dos grupos de acessos foram revelados em média 10 alelos e 5 alelos efetivos por loco. Quanto à frequência de alelos privados, no grupo de acessos de $E$. oleracea foi de 0,033 e 0,167 , em $E$. edulis variou de 0,01 a 0,177 e nos híbridos de 0,2 a 0,088 . Enquanto que, em cada grupo os valores de $\mathrm{N}_{a}$ foram de 12, 15 e 4 para $\mathrm{H}$, EE e EO, respectivamente.

Tabela 1. Estimativas de parâmetros genéticos em três grupos de acessos de Euterpe spp. a partir de seis locos microssatélites. $\mathrm{Pb}=$ pares de base; $\mathrm{Na}=$ número de alelos; $\mathrm{Ne}=$ número efetivo de alelos; $\mathrm{Ap}=$ alelos privado; $\mathrm{PlC}=$ conteúdo de informação polimórfica.

\begin{tabular}{|c|c|c|c|c|c|c|}
\hline Grupos & Locos & $\begin{array}{c}\text { Amplitude } \\
\left(P_{\mathrm{b}}\right)\end{array}$ & $\mathbf{N}_{\mathrm{a}}$ & $\mathrm{N}_{\mathrm{e}}$ & $A_{p}$ & PIC \\
\hline \multirow{6}{*}{ Híbridos } & EE03 & $118-253$ & 12 & 3,2 & 2 & 0,681 \\
\hline & EE45 & $111-247$ & 9 & 2,0 & 4 & 0,489 \\
\hline & EE47 & $113-276$ & 15 & 5,7 & 5 & 0,814 \\
\hline & EE52 & $221-269$ & 14 & 4,0 & 3 & 0,739 \\
\hline & EE54 & $138-181$ & 13 & 9,5 & - & 0,886 \\
\hline & EE59 & $96-181$ & 13 & 8,2 & 4 & 0,868 \\
\hline Média & & & 12,6 & 5,46 & & 0,746 \\
\hline \multirow{6}{*}{ E. edulis } & EE03 & $217-251$ & 16 & 10,96 & 6 & 0,901 \\
\hline & EE45 & $104-132$ & 9 & 2,80 & 4 & 0,619 \\
\hline & EE47 & $237-286$ & 16 & 7,97 & 7 & 0,862 \\
\hline & EE52 & $221-280$ & 20 & 10,0 & 9 & 0,893 \\
\hline & EE54 & $128-179$ & 20 & 10,1 & 5 & 0,894 \\
\hline & EE59 & $96-128$ & 9 & 6,96 & 2 & 0,841 \\
\hline Média & & & 15 & 8,14 & & 0,835 \\
\hline \multirow{6}{*}{ E. oleracea } & EE03 & $214-217$ & 2 & 1,38 & 1 & 0,239 \\
\hline & EE45 & $111-113$ & 2 & 1,22 & - & 0,164 \\
\hline & EE47 & $233-237$ & 2 & 1,64 & - & 0,315 \\
\hline & EE52 & 221 & 1 & 1 & - & 0,0 \\
\hline & EE54 & $138-181$ & 13 & 9,37 & 1 & 0,884 \\
\hline & EE59 & $106-167$ & 4 & 1,32 & - & 0,232 \\
\hline Média & & & 4 & 2,65 & & 0,305 \\
\hline
\end{tabular}


Houve diferença significativa $(p<0,001)$ das fontes de variação da AMOVA, cuja a variação foi composta por $13 \%$ entre os grupos e 47 e $40 \%$ entre os acessos e dentro dos acessos, respectivamente (Tabela 2).

$\mathrm{Na}$ matriz de distância genética formada pelos 81 acessos foram obtidos valores heterogêneos, indo desde muito similares (1) a dissimilares (22). Os acessos mais divergentes foram EO299/EE351 (22), enquanto que os acessos mais divergentes para retrocruzamentos foram H309/EE284 (17) e H324/EO250 (14) no caso de combinações com E. oleracea. Considerando os cruzamentos intraespecificos, a combinação com maior divergência entre os acessos de E. edulis seria EE351/EE342(19) e entre os acessos de E. oleracea seriam EO250/EO244, EO250/EO252 e EO250/EO254 (10).

A utilização do modelo com base em estatística bayesiana permitiu identificar quatro grupos (Figura 1) com um valor $F_{\text {st }}$ igual 0,4214 .

O dendograma gerado apresentou correlação cofenética de 0,805 ( $p<0,0001)$. Com $50 \%$ do valor de distância, possibilitou averiguar quais acessos formaram os quatro grupos, que foram assim representados: I - O maior grupo com 35 acessos, sendo 15 de EO, 16 de $\mathrm{H}$ e 4 de EE; II - 12 acessos de EE; III - 16 acessos de EE e IV com 18 acessos, sendo 16 de EE e dois de $H$. São formados vários subgrupos com acessos com menos de $10 \%$ de dissimilaridade, que podem ser visualizados em todos os grupos (Figura 2).

\section{DISCUSSÃO}

Entre os SSR transferidos para E. oleracea no presente estudo, quatro deles (EE45, EE47,EE52 e EE59) nunca haviam sido empregados nesta espécie, sendo os locos EE2, EE3, EE8, EE15, EE23, EE43 e EE54 os únicos que já foram utilizados anteriormente (Gaiotto et al., 2001; Oliveira \& Silva, 2008; Oliveira et al., 2010).
Azevedo et al. (2018) confirmaram a eficiência dos 18 loci em E. precatória, sendo que entre estes, EE2, EE3, EE8, EE15 e EE43 também já foram empregados com sucesso em acessos da cultura do dendê (Elalis guinensis) (Costa et al., 2012).

A transferência desses marcadores é possível devido à conservação de sítios que flanqueiam os microssatélites (Ferreira \& Gratapalgia, 1998; Alves, 2002; Pinto, 2007). No gênero Euterpe, Oliveira et al. (2016) constataram que E. precatória possui um genoma maior que o de $E$. edulis e $E$. oleracea, sendo os arranjos estruturais dos cromossomos as principais forças de evolução que atuam sobre o cariótipo, o que faz com que as espécies possuam um nível intermediário de evolução dentro da família. Esta é uma característica desejável, principalmente tratandose de espécies com potencial econômico ou ecológico, pois diminui o tempo e os custos empregados nas análises (Ferreira \& Gratapalgia, 1998; Alves, 2002; Pinto, 2007).

Os seis locos transferidos detectaram níveis heterogêneos de variação genética molecular nos grupos avaliados. A variabilidade alélica foi inferior em $E$. oleracea, sendo que entre os quatro alelos revelados nesse grupo, dois foram privados e apresentaram frequências superiores a 0,03, portanto contribuíram para as estimativas de diversidade. O PIC também foi inferior nesse grupo. Segundo Botstein et al. (1980) valores de PIC acima de 0,5 são altamente satisfatórios e representam o alto poder discriminatório do marcador, enquanto que valores entre 0,5 e 0,3 são medianos e menores que 0,200 são baixos e indicam baixo poder discriminatório dos locos. A partir dessa abordagem, com exceção do EE54 e EE47, os demais locos foram pouco polimórficos, com baixo poder de discriminação. Além disso, nesses acessos o EE52 foi monomórfico, segundo Azevedo et al. (2018) isso pode ser uma consequência de que o loco seja parte de fragmentos de genes conservados.

Tabela 2. Análise de variância molecular. Referencias: GL grau de liberdade; SQ soma dos quadrados; MQ média dos quadrados.

\begin{tabular}{lccccc}
\hline \multicolumn{1}{c}{ Fonte } & GL & SQ & QM & $\begin{array}{c}\text { Estatística } \\
\text { de variação }\end{array}$ & $\begin{array}{c}\text { \% } \\
\text { Variação }\end{array}$ \\
\hline Entre grupos & 2 & 79043,391 & 39521,695 & 688,775 & 13 \\
Entre acessos & 79 & 578064,798 & 7317,276 & 2565,300 & 47 \\
Dentro acessos & 82 & 179307,500 & 2186,677 & 2186,677 & 40 \\
\hline Total & 163 & 836415,689 & & 5440,751 & 100 \\
\hline
\end{tabular}

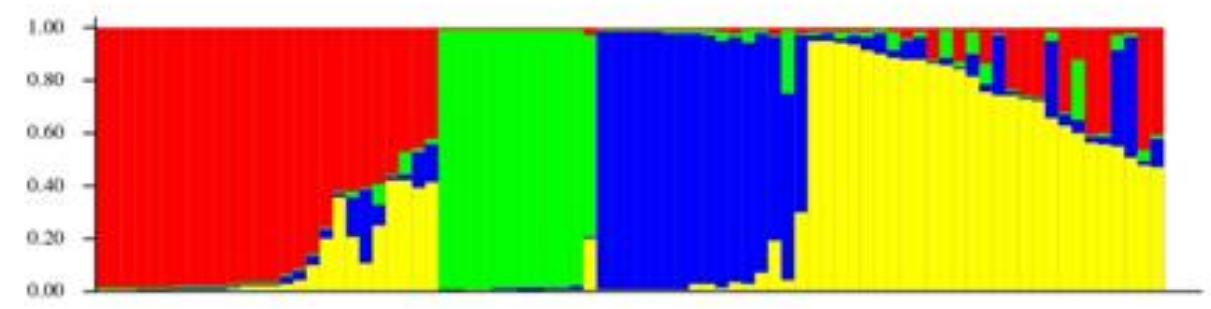

Figura 1. Agrupamento dos acessos para $\mathrm{K}=4$. 
Revista de la Facultad de Agronomía, La Plata (2020) Vol 119 (1): 1-7

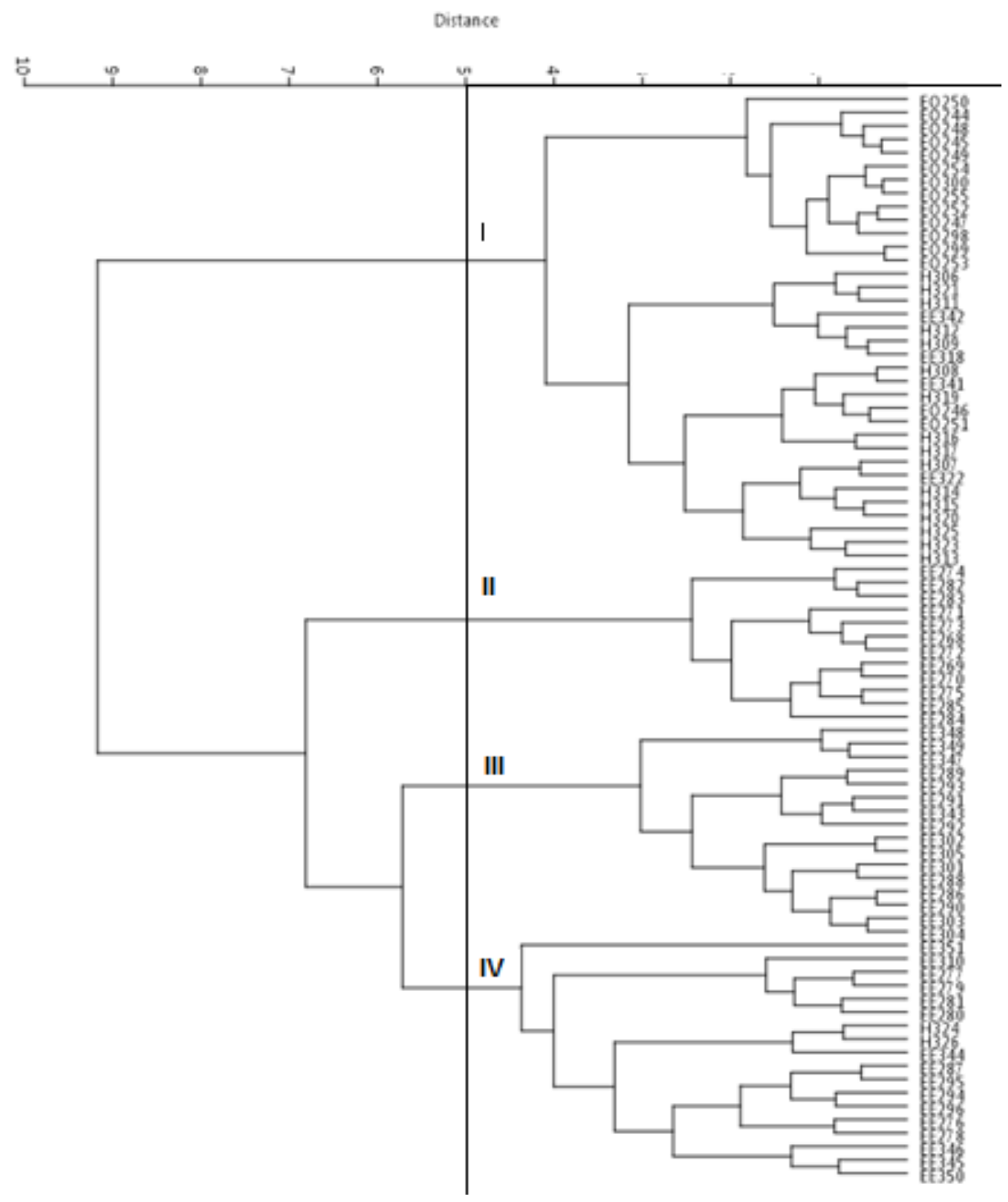

Figura 2. Agrupamento pelo método Ward entre acessos de Euterpe spp. da coleção da Empresa de Pesquisa Agropecuária e Extensão Rural de Santa Cataria - Estação Experimental de Itajaí - EPAGRI - EEI. Grupos formados a partir de $50 \%$ de dissimilaridade.

Para os demais grupos de acessos, os níveis de variabilidade alélica e polimorfismos foram altos em todos os locos, equivalentes ou superiores ao detectado em populações e acessos de E. oleracea localizados na região amazônica (Oliveira et al., 2010; Costa et al., 2012; Benvindo et al., 2017; Azevedo et al., 2018) e populações naturais de E. edulis (Gaiotto et al., 2003; Conte et al., 2008). Os resultados indicam que o número de amostras pode ter sido limitado para detectar alelos com frequências baixas nos acessos de $E$. oleracea, o que provavelmente não ocorreu nos demais grupos.

A partir da AMOVA constatou-se diferença significativa entre os três grupos, indicando estruturação genética, que pode ser atribuída à divergência genética que existe entre as espécies $E$. oleracea e $E$. edulis, que possuem origens e perfis genéticos distintos (Sawazaki et al., 1998; Martins et al., 2007). No entanto, a maior variabilidade está distribuída entre e dentro dos acessos que compõem os três grupos. Os resultados obtidos a partir da abordagem bayesiana corroboram com resultados da AMOVA, pois, a formação de quatro grupos fortalece a hipótese de existência de estruturação genética, sendo que o conjunto dos genótipos avaliados pode ser considerado diversificado e promissor para formação de combinações para programas de melhoramento.

A correlação cofenética foi alta, indicando concordância entre os valores de dissimilaridade e matriz usada para o agrupamento pelo método Ward. Quando cortado a partir de $50 \%$ do valor de dissimilaridade a formação dos quatros grupos fica visível, sendo condizente com resultado obtido pelo método com estatística bayesiana. Os resultados obtidos permitem inferir que 
existe sub estruturação dentro do grupo de acessos de E. edulis que compõe a coleção da EEI. Estes resultados indicam também uma maior similaridade entre os acessos de $E$. oleracea e híbridos, o que levou a maioria deles pertencerem a um único grupo. Resultado similar foi obtido com emprego de isoenzimas em Euterpe spp. da coleção de germoplasma do Instituto Agronômico de Campinas, na qual os híbridos também se apresentaram mais próximos de $E$. oleracea, espécie utilizada como progenitor feminino (Sawazaki et al., 1998).

Os resultados possibilitam a instrução das combinações com maior divergência, sendo o cruzamento mais divergente aquele entre acessos das distintas espécies, como já era esperado. No entanto, a alta divergência entre os acessos de $E$. edulis e a sub estruturação desse grupo indica o potencial dos cruzamentos intraespecificos entre acessos dessa espécie. A alta diversificação entre e dentro de indivíduos dessa espécie é corriqueiramente relatada em estudos desenvolvidos em populações naturais, sendo relacionada a diversos fatores: funcionamento do sistema reprodutivo, padrões de dispersão de pólen e sementes, grau de fragmentação e conservação de remanescentes florestais, além da procedência geográfica (Gaiotto et al., 2003; Conte et al., 2008). Pode-se considerar que esse grupo de genótipos atende o objetivo inicial da formação da coleção de campo da EEI com esta espécie.

Os cruzamentos entre acessos da espécie $E$. oleracea seriam os com menor divergência, o que pode ser justificado pela característica dos genótipos estudados, que já passaram por algum processo de seleção antes de serem introduzidos nessa região. Os retrocruzamentos com esta espécie seriam menos divergentes em comparação com os retrocruzamentos com acessos de $E$. edulis. Apesar de não terem sido detectados acessos idênticos, são desestimuladas as combinações que apresentaram alta proximidade genética $(\geq 10)$, conforme anteriormente sugerido para coleções de germoplasma de açaizeiros da Amazônia (Oliveira et al., 2010).

Apesar dos híbridos Euterpe comercialmente cultivados nas regiões sul serem formados por polinização aberta, através do consórcio entre açaizeiros e palmeira juçara (Venturieri et al., 2016; Zambonim et al., 2016), o retrocruzamento por polinização controlada é relatado por Campos et al. (1991), com a formação do hibrido (E. oleracea $\times$ E. edulis) $\times$ E. edulis, indicando que esta já foi uma possibilidade testada para combinação e fixação de caracteres desejáveis. Neste contexto, os resultados obtidos são importantes para instrução das melhores combinações entre os acessos das espécies com os híbridos, indicam que neste caso, a maior diversidade pode ser obtida a partir do uso de alguns acessos de $E$. edulis como genitores.

\section{CONCLUSÃO}

Os seis marcadores empregados foram altamente polimórficos para o conjunto de acessos avaliados e eficientes para estimar a variabilidade entre e dentro dos grupos, permitindo a distinção dos genótipos mais similares e mais divergentes. A diversidade encontrada possibilitará a orientação de cruzamentos dirigidos, tanto para formação de híbridos intra e interespecíficos como para retrocruzamentos.

\section{Agradecimentos}

A Capes pela concessão da bolsa de doutorado, a FAPESC pelo financiamento do trabalho, a EPAGRI$\mathrm{EEI} e$ ao programa de pós-graduação em Agroecossistemas da UFSC-SC pelo apoio e estrutura disponibilizada.

\section{REFERÊNCIAS}

Aguiar, M.S., D.F. Ferreira, A.M. Aguiar, O. Bison, G.D.S.P. Rezende \& D. Grattapaglia. 2007. Potencial de híbridos entre clones-elite de eucalipto por meio de marcadores microssatélites. Pesquisa Agropecuária Brasileira 7: 1007-1012.

Alves, R.M. 2002. Caracterização genética de populações de cupuaçuzeiro, Theobroma grandiflorum (Willd. ex. Spreng.) Schum., por marcadores microssatélites e descritores botânico-agronômicos. Tese de Doutorado em Genética e Melhoramento de Plantas, Universidade de São Paulo, São Paulo, Brasil. 146 pp.

Azevedo, H.D.S., P.B. Rufino, L.D.N. Cavalcante, J.M.A. de Azêvedo, L.D.O. Wadt \& T.D. Campos. 2018. Avaliação da transferibilidade para Euterpe precatória de marcadores microssatélites desenvolvidos para Euterpe edulis. Congresso Norte - Nordeste de pesquisa e Inovação, Porto Velho, Rondônia.

Benvindo, F.D., I.D.N. Cavalcante, H.D.S. Azevedo \& T.D. Campos. 2017. Diversidade genética de açaizeiro (Euterpe precatória) no município de Feijó, Acre. Seminário de Iniciação Científica da UFAC, Rio Branco, Acre.

Bovi, M.L.A. 1984. Pesquisas em desenvolvimento com o açaizeiro no Instituto Agronômico, Estado de São Paulo. O Agronômico. Publicação técnica N 2. 178 pp.

Bovi, M.L.A., G.G. Júnior \& L.A. Sáes. 1987. Híbridos interespecíficos de palmiteiro (Euterpe oleracea $\mathrm{x}$ Euterpe edulis). Bragantia 2: 343-363.

Botstein, D., R.L. White, M. Skolnick, \& R.W. Davis. 1980. Construction of a genetic linkage map in man using restriction fragment length polymorphisms. American Journal of Human Genetics 3: 314 .

Cavalcante, L.D.N., H.D.S. Azêvedo \& T.D. Campos. 2018. Utilização de marcadores microssatélites heterólogos de açaí solteiro. Reunião anual da SBPC UFAL, Maceió, Alagoas.

Campos D.S., M.L.A. Bovi \& M. Laderoza. 1991. Caracterização do palmito obtido de algumas combinações híbridas entre Açaí e Juçara cultivadas sob diferentes condições. Pesquisa Agropecuária Brasileira 5: 637-646.

Chagas, P.T.K., R.F. Sousa, C.G. Fajardo \& F. Almeida Vieira. 2015. Seleção de marcadores ISSR e diversidade genética em uma população de Elaeisguineensis. Revista Brasileira de Ciências Agrárias 10.

Conte, R., M.S. dos Reis, A. Mantovani \& R. Vencovsky. 2008. Genetic structure and mating system 
of Euterpe edulis Mart. populations: A comparative analysis using microsatellite and allozyme markers. Journal of Heredity 5: 476-482.

Costa, M., M. Oliveira, S.V. do Nascimento \& C.D.A. Silva. 2012. Transferibilidade de iniciadores microssatélites de açaizeiro (Euterpe oleracea) para dendenzeiro (Elaeis guinensis). Congresso Brasileiro de Recursos Genéticos. Anais da Sociedade Brasileira de Recursos Genéticos, Belém, Pará.

Cruz, T.V., M.M. Souza, F.A. Roza, A.J.C. Viana, G.O. Belo \& J.W.S. Fonseca. 2008. Germinação in vitro de grãos de pólen em Passiflora suberosa L. para sua utilização em hibridação interespecífica. Revista Brasileira de Fruticultura 30: 875-879.

Doyle J. 1991. DNA protocols for plants. Molecular techniques in taxonomy. Heidelberg 57: 283-293.

Falush, D., M. Stephens \& J.K. Pritchard. 2003. Inference of population structure using multilocus genotype data: Linked loci and correlated allele frequencies. Genetics 164: 1567-1587.

Ferreira, M.E \& D. Grattapaglia. 1998. Introducción al uso de marcadores moleculares en el análisis genético. Brasília. 220 pp.

Furlan, R.D.A., E.S. Mori, E.V. Tambarussi, C.B.D. Moraes, F.A.D. Jesus \& L. Zimback. 2007. Estrutura genética de populações de melhoramento de Pinus caribaea var. hondurensis por meio de marcadores microssatélites. Bragantia 553-563.

Kiyuna, I., M.M.D. Santiago \& M.L.A. Bovi. 1997. Simulação da viabilidade econômica da cultura do palmiteiro híbrido (Euterpe oleracea X Euterpe edulis) no estado de São Paulo. Informações Econômicas 4: 25-40.

Gaiotto, F.A., R.P.V. Brondani \& D. Grattapaglia. 2001. Microsatellite markers for heart of palm - Euterpe edulis and Euterpe oleracea Mart. (Arecaceae). Molecular Ecology Notes 2: 86-88.

Gaiotto, F.A., D. Grattapaglia \& R. Vencovsky. 2003. Genetic structure, mating system, and long-distance gene flow in heart of palm (Euterpe edulis Mart.). Journal of Heredity 5: 399-406.

Hammer, Ø., D.A. Harper \& P.D. Ryan. 2001. PAST: paleontological statistics software package for education and data analysis. Palaeontologia Electronica 4: $1-9$

Kalinowski, S.T., M. L. Taper \& T.C. Marshall. 2010. Revising how the computer program CERVUS accommodates genotyping error increases success in paternity assignment. Molecular Ecology 19:1512-1512. Lanza, M.A., C.T. Guimarães \& I. Schuster. 2000. Aplicação de marcadores moleculares no melhoramento genético. Informe Agropecuário 21: 97108.

Manfio, C.E., S.Y. Motoike, M.D.V. de Resende, C.E.M. dos Santos \& A.Y. Sato. 2012. Avaliação de progênies de macaúba na fase juvenil e estimativas de parâmetros genéticos e diversidade genética. Pesquisa Florestal Brasileira 69: 63.

Marshall, T.C., J.B.K.E. Slate, L.E. Kruuk \& J.M. Pemberton. 1998. Statistical confidence for likelihood-based paternity inference in natural populations. Molecular Ecology 7: 639-655.

Martins, C.C., M.L.A. Bovi, E.S. Mori \& J. Nakagawa.
2007. Isoenzimas na diferenciação de sementes de três espécies do gênero Euterpe. Revista Árvore 31: 51-57.

Oliveira, M.S.P \& K.J.D.E. Silva. 2008. Diferenciação genética entre procedências de açaizeiro por marcadores RAPD e SRR. Revista Brasileira de Fruticultura 30: 438-443.

Oliveira, M.S.P., J.B. Santos, E.P. Amorim \& D.F. Ferreira. 2010. Variabilidade genética entre acessos de açaizeiro utilizando marcadores microssatélites. Ciência Agrotécnica 34: 1253 -1260.

Oliveira, M.S.P., J. Pérez-Jiménez, S. Arranz, R.E. Alves, E.S. de Brito, M.S. Oliveira \& F. Saura-Calixto. 2011. Açaí (Euterpe oleracea) 'BRS Pará: A tropical fruit source of antioxidant dietary fiber and high antioxidant capacity oil. Food Research International 7: 2100-2106.

Oliveira, L.C., M.D.S.P. de Oliveira, L.C. Davide \& G.A. Torres. 2016. Karyotype and genome size in Euterpe Mart. (Arecaceae) species. Comparative Cytogenetics 10:17-25.

Peakall, R.O.D \& P.E. Smouse. 2006. Genalex 6.0 genetic analysis in Excel. Population genetic software for teaching and research. Molecular Ecology notes 1: 288-295.

Pinto, M.F.F.C. 2007. Caracterização de locos microssatélites em duas de abelhas espécies da região amazônica: Melipona compressipes e Melipona seminigra (Hymenoptera: Apidae: Meliponina). Dissertação de Mestrado em Genética, Conservação e Biologia Evolutiva, Instituto Nacional de Pesquisas da Amazônia, Manaus, Brasil. 66 pp.

Pritchard, J.K., M. Stephens \& P.J. Donnelly. 2000. Inference of population structure using multilocus genotype data. Genetics155: 945-959.

Rocha, M.D.G., I.E. Pires, R.B. Rocha, A. Xavier \& C.D. Cruz. 2007. Seleção de genitores de Eucalyptus grandis e de Eucalyptus urophylla para produção de híbridos interespecíficos utilizando REML/BLUP e informação de divergência genética. Revista Árvore 31: 977-987.

Sawazaki, H.E., M.L.A. Bovi, L. Sodek \& C.A. Colombo. 1998. Diversidade genética em palmeiras através de isoenzimas e RAPD. Revista Brasileira de Biologia 58: 681-691.

Schuelke, M. 2000. An economic method for the fluorescent labeling of PCR fragments. Nature Biotechnology 18: 233-234.

Weir, B.S. 1996. Genetic data analysis. Methods for discretion population genetic data. Sinauer Associates, Sunderland. $377 \mathrm{pp}$.

Venturieri, G.A., J.F. Santos, F.M. Zambonim \& P.R.M. Miller. 2016. Histórico e metodologia usadas para formar os híbridos de Euterpe oleracea $\mathrm{x}$ Euterpe edulis pelo agricultor Jorge Leite Tuzino. Congresso Brasileiro de Fruticultura. Anais Sociedade Brasileira de Fruticultura, São Luiz, Maranhão.

Zambonim, F.M., G.A.Venturieri, K.H.Mariguele, P.R.M. Miller \& J.F. Santos. 2016. Frequêcia de morfotipos de plântulas obtidas da hibridação espontânea entre Euterpe oleracea $x$ Euterpe edulis em clima subtropical. Congresso Brasileiro de Fruticultura. Anais Sociedade Brasileira de Fruticultura, São Luis, Maranhão. 